\title{
Relationship between Multiple Intelligence, Reading Proficiency, and Implementing Motivational Strategies: A Study of Iranian Secondary Students
}

\author{
Ensieh Fayazi-Nasab \\ Department of English, Khorasan e Razavi Science and Research Branch, Islamic Azad University, Neyshabur, Iran \\ Department of English, Neyshabur Branch, Islamic Azad University, Neyshabur, Iran \\ Email: efayazinasab@yahoo.com \\ Narjes Ghafournia (Corresponding author) \\ Department of English, Neyshabur Branch, Islamic Azad University, Neyshabur, Iran \\ E-mails: narjesghafournia@yahoo.com,na.ghafournia@gmail.com
}

Received: 30-05- 2016

doi:10.7575/aiac.ijels.v.4n.3p.34
Accepted: 24-06-2016

URL: http://dx.doi.org/10.7575/aiac.ijels.v.4n.3p.34
Published: 31-07-2016

\begin{abstract}
There exist many factors, affecting reading ability. Multiple intelligence and motivational strategies are among the factors that seem to make significant contribution to the reading process. Thus, the present study probed the probable significant relation between Iranian language learners' multiple intelligences and reading ability. The study also probed the effectiveness of implementing motivational strategies and language learners' reading ability. Finally, it probed the significant correlation with implementing certain motivational strategies and reading ability. The design of this study is correlational design since the relationship between dependent and independent variables were investigated through correlation coefficient. The participants were females in the final year of the secondary education level. Using treatment and the two questionnaires of motivational strategies and multiple intelligences, the findings demonstrated significant correlation between verbal/linguistic intelligence and reading ability as well as the significant correlation between implementing certain motivational strategies and reading ability. In addition, the essence of teaching motivational strategies was confirmed through the significant difference between the results of pretest and posttest as the result of teaching the participants certain motivational strategies by the researchers. The findings have pedagogical implications for language teachers to improve the reading ability of the students substantially.
\end{abstract}

Keywords: Motivational strategies; reading ability; verbal intelligence; multiple intelligence

\section{Introduction}

Language teaching is by nature different from teaching other content material. A language is a main part of the culture of a people, and the way they communicate in their daily lives. Therefore, it could be appealing by itself to the learners. However, in our general education, the textbooks are compiled in a way to present the utmost level of context-reduced content in terms of the cultural characteristics of the target culture. These facts have led to a general lack of interest regarding learning English, at least as long as the general education is concerned. In such a setting, presenting motivational strategies and giving the capacity of self-motivation to learners could be highly influential. Motivation, as an extra-linguistic factor, is commonly overlooked to the benefit of linguistic elements in language classrooms. Dörnyei's (1995) comprehensive collection of strategies, which focuses on the three stages of generating initial motivation, maintaining motivation, and self-evaluation, could best be favored by our teachers and students as a new capacity to boost learning. In their study, Bankier and Wright (2012) concluded that some motivational strategies required specific activities in order to incorporate them into different classrooms. In this study, one question is what strategies are congruent with Iranian students; or to put it another way, if there are some strategies that are applicable to Iranian schools setting. Furthermore, this study aimed to find any possible significant relationship between students' intelligences and their appraisal of the effectiveness of every motivational strategy, employed by their teacher. In the context of Iranian general education, reading proficiency is highlighted more than other skills. In fact, based on the opinions of many Iranian teachers, the main goal of the English textbooks is to develop students' reading proficiency. Owing to the importance attached to reading skill, attempt was made to view the effect of motivational strategies in the light of multiple intelligences in reading comprehension.

Reading comprehension can be a boring task if the subject or the method used to approach it is less of a communicative nature. Part of this problem could be resolved by the learner, but with the help from the instructor. This asks the teacher to consider intrinsic motivation very important. Intrinsic motivation was defined as a) the learners' participation in 
instructional activities due to curiosity; (b) the desire to involve in an instructional activity just for the matter of participation and task accomplishment; and (c) for the sake of instructional contribution (Dev, 1997).

Intrinsic motivation is concerned with persistence and trial by language learners. The language learners, having much intrinsic motivation, certainly develop major goals such as comprehensive learning and achieving comprehensive knowledge. The desire to understand fully a reading comprehension text and topic has been demonstrated to significantly correlate with applying effective language learning strategies, having positive attitudes toward language learning, the kind of task accomplishment, perceived reading ability, consciousness, persistence, use of self- regulatory strategies, and involvement in deeply cognitive processes, (Archer, 1994; Garcia \& Pintrich, 1996; Greene, Miller, Montalvo, Ravindran, \& Nichols, 1996).

Based on the results of the studies on intrinsic and extrinsic motivation, language learners can be divided into three basic academic groups. The first group has a comprehensive knowledge on how to accomplish a task. The second group focuses on ego aspects. The third group knows how to avoid the tasks they do not have necessary knowledge. In other words, they have work avoidant orientation (Deci \& Ryan, 1985).However, extrinsic motivation refers to motives that are outside and separate from the behaviors they cause.

Concerning intelligences, intrinsic motivation can stem from different areas of interest mainly determined by one's developed intelligences. Selection of reading tasks and reading materials, which go with a wide range of intelligences, could be of help in increasing intrinsic motivation. As Dörnyei (2001) puts it, motivating in a general sense is known to the teachers, "along the lines of if you do this, you'll get this". However, in practice, motivation seems to take more than this axiomatic knowledge. Much of motivation should normally stem from the inherent appeal of the task itself. This is to say that learning should be connected to its real-life applications. Despite the development of new communication technologies, which are mostly mediated through English in EFL context of learning, students might not readily touch the excitement to use it in their everyday life. This lack of accessibility could explain at least part of the general disfavor that students surface in language classes.

In an ideal world, where the learners' curiosity and inherent motivation has not yet been curbed or diminished by a student-unfriendly school system, all learners are interested in learning, which has a lot of intrinsic pleasure for them. Nevertheless, instead of keen pupils, who according to the theory, should be eagerly absorbing the morsels of wisdom offered to them, reluctant youngsters are found who not aware of the fact that they should

Despite the fact that motivation has been documented as a key feature in learning languages, it has not been well researched, especially in terms of the adaptability and preference of different motivational strategies in different contexts and cultures. In this study, attempt was made to view how multiple intelligences and motivational strategies probably affect reading comprehension. Also, owing to the fact that motivational strategies have been shown flexible and adaptable, or in some cases necessary to be adapted, this study tries to find out the motivational strategies, which are favored by Iranian students and applicable to this setting.

Concerning the intelligences, there is a general consensus that identifying the learners' intelligence profile is a useful act. However, there are also some studies, whose results have implied otherwise. A review of the literature shows that a few studies have been rigorously carried out to probe the role of multiple intelligences theory in the process of reading comprehension by EFL learners. Thus, this fact necessitates more extensive studies in this domain.

As English language teaching gains more importance all over the world, special attention is given to the implementation of new teaching methods, which deal with an appreciation of the students' individuality and uniqueness. It is hoped that the findings of this study can shed light on the language learners' learning preferences. The present study is an elaboration on the probable significant correlation between applying certain motivational strategies and reading proficiency of Iranian language learners. Furthermore, it seeks the probable significant correlation between Iranian language learners multiple intelligence and reading proficiency. More specifically, the study explores the answer to the following research questions.

\subsection{Research Questions}

1. Is there any significant relationship between Iranian EFL learners' multiple intelligences and reading proficiency?

2. Does incorporating motivational strategies in the class have any significant effect on reading proficiency?

3. Is there any significant relationship between Iranian EFL learners' preference for motivational strategies and reading proficiency?

1.2 Research Hypotheses

In order to investigate the aforementioned research questions, the researchers formulated the following null hypotheses:

1. There is not any significant relationship between Iranian EFL learners' multiple intelligences and reading proficiency.

2. Incorporating motivational strategies in the class does not have any significant effect on reading proficiency.

3. There is not any significant relationship between Iranian EFL learners' preferences for motivational strategies and reading proficiency. 


\section{Methodology}

\subsection{Participants}

The participants consisted of 100 Iranian English learners, studying at the final year of high school. They were female, whose ages were between 17 to 18 years old. With regard to their scores on the reading proficiency test, only the students (100) at intermediate level were selected. Initially, there were 154 students, who took the reading section of the Introductory Preparation TOEFL Test as the standard test of proficiency. The selected students were randomly distributed into five classes, each consisting of 20 students.

\subsection{Instruments}

A reading proficiency test, derived from Introductory Preparation TOEFL Test with 50 reading comprehension items, was used by the researchers. The test was in multiple- choice format. The reliability index, calculated by KR 21 was 0.80 . The devoted time to answer the test was 50 minutes.

There is a reading comprehension test, which was administered to the selected sample. The test was used as a pretest to homogenize the participants. This is the reading section of a standard achievement test for the students who are at the intermediate level, derived from Steps to Understanding Test book. This section incorporates a reading text with 30 questions. The time for this test was 30 minutes. The reliability index, using Cronbach formula, is 0.89 , which is acceptable.

The post-test is another reading comprehension test from the same source (Steps to Understanding Test book) with the same format. The alpha reliability index, using Cronbach alpha is 0.81 , which is acceptable. The participants' performance on this test tells us about the possible effect of the motivational strategies. The results on this test were compared with the results of the pre-test. The purpose of this comparison is to find out the effectiveness of the treatment sessions through which the motivational strategies were applied. To this purpose, the matched t-test was used. This method of analysis was used to compare the means of two different tests of the same group.

Multiple Intelligence Questionnaire was another instrument derived from Gardner's (1983) Intelligence Quotient test. It included 70 items. It was piloted on 30 similar participants. The reliability index, using Cronbach alpha, was .92, which was a high index. The dedicated time to respond the questionnaire was 40 minutes. To remove the probable ambiguities, the questionnaire was translated into Persian, the mother tongue of the participants. In addition, three language teaching experts reviewed the questionnaire to check the face validity and content validity of the questionnaire.

Motivational Strategy Questionnaire was another instrument used in this study. Ten motivational strategies out of 35 available strategies were selected as the most practiced ones based on teacher's experience. There is also a questionnaire that asks about the students' ideas about the practicality of these strategies. The reliability index of the questionnaire using Cronbach alpha is 0.90 , which is very high. The dedicated time to respond the questionnaire was 10 minutes. The questionnaire was translated into Persian and was checked by three language teaching experts.

\subsection{Treatment}

Ten motivational strategies were used in a course of 20 class sessions in general high school to female students. The researchers make use of ten out of thirty five of the motivational strategies, which are mentioned in the following. These ten strategies were arrived based on teacher's judgment of their practicality, significance, and students' needs. All the students received this treatment.

The strategies that the teacher incorporated in the teaching process during the treatment sessions are as follows based on Dörnyei, (2001, p.110):

1. Demonstrate and talk about your own enthusiasm for the course material, and how it affects you personally.

2. Take the students' learning very seriously.

3. Promote the learners' language-related values by presenting peer role models.

4. Raise the learners' intrinsic interest in the L2 learning process.

5. Promote 'integrative' values by encouraging a positive and open-minded disposition towards the L2 and its speakers, and towards foreignness in general.

6. Promote the students' awareness of the instrumental values associated with the knowledge of an L2.

7. Make learning more stimulating and enjoyable by breaking the monotony of classroom events.

8. Build your learners' confidence by providing regular encouragement.

9. Increase student motivation by promoting cooperation among the learners.

10. Use grades in a motivating manner, reducing as much as possible their demotivating impact.

Among these ten strategies, strategies 1 and 6 were implemented by communicating them to the students, namely, showing and talking about their enthusiasm and increasing their awareness of the instrumental benefits of learning English. The other eight strategies were embodied in terms of behavioral traits; that is to say, the teacher included these strategies in her class sessions.

2.4 Procedure

The first step after sampling is setting up the treatment sessions. The teacher at her disposal had certain classes, which she taught as their English instructor. These were five classes with an average of 20 students. All the students were female at general high schools in the final year of the three-year secondary school education. The fact that there are 
some extraneous cases in every class and owing to the fact that the population was not big enough to allow simple random sampling, an initial reading test ( test of reading proficiency) was administered, the details of which was stated above. Through this test, screening a more homogeneous sample became available.

The treatment sessions, which included 20 sessions, featured the ten motivational strategies, mentioned earlier. Dörnyei (2001) enumerates 35 strategies; however he acknowledged that not all these strategies are applicable to a given class. Therefore, ten cases, which seemed to be more relevant and applicable, based on the teacher's experience, were selected. At the end, the students assessed the usefulness of these strategies through a questionnaire they filled in.

In addition, the effectiveness of teaching motivational strategies was investigated through administrating pre-test and post-test to the students. Through a further questionnaire, the researcher surveyed the students' multiple intelligences.

\subsection{Data Analysis}

The more frequent data analyses, applied in the present study, were descriptive statistics, matched T-test, and correlation coefficient.

\section{Results}

\subsection{Results of the Correlation for the First Hypothesis}

The first null hypothesis states that no significant relationship exists between the intelligences and reading proficiency. However, as long as the Linguistic/Verbal intelligence is concerned, there is a significant relationship between the two. This correlation coefficient is significant at level of 0.01 . Table 1 gives more details on this correlation.

Table 1. Correlation of Linguistic/ Verbal Intelligence and Reading Ability

\begin{tabular}{cccc}
\hline & & Linguistic/ Verbal & Post-test \\
\hline Linguistic/ Verbal & Pearson & 1 & $.299^{* *}$ \\
Reading Ability (Post- & Correlation & 100 & .002 \\
test) & Pearson & $.299^{* *}$ & 1 \\
& Correlation & .002 & 100 \\
\hline
\end{tabular}

\footnotetext{
**. Correlation is significant at the 0.01 level (2-tailed).
}

Such a correlation was also reported in some studies (Gaines \& Lehmann, 2002; Owolabi \& Okebukola, 2009). It seems that linguistic intelligence is significantly correlated with the reading ability, shown in the table as the scores of the reading posttest.

\subsection{Results of the Second Hypothesis}

This hypothesis pertains to the difference of performance of the sample on the two tests. The employed matched t-test procedure showed that the students really benefitted from the treatment. Table 2 displays the statistics of the pair of the two tests.

Table 2. Descriptive Statistics of Pretest and Posttest

\begin{tabular}{ccccc}
\hline & Mean & $\mathrm{N}$ & Std. Deviation & Std. Error Mean \\
\hline Pre-test & 12.8500 & 100 & 2.77934 & .27793 \\
Post-test & 13.7500 & 100 & 2.90028 & .29003 \\
\hline
\end{tabular}

As displayed in Table 2, the standard deviation on the post-test increased slightly, however, the mean score witnessed a meaningful rise. The result of the matched T-test computation of the two tests is presented in Table 3 . The relationship is computed to a degree of freedom of $\mathrm{N}-1$.

Table 3. Paired Samples t-test

\begin{tabular}{|c|c|c|c|c|c|c|}
\hline & & \multicolumn{2}{|c|}{$95 \%$ Confidence Interval } & \multirow[t]{2}{*}{$\mathrm{t}$} & \multirow[t]{2}{*}{$\mathrm{df}$} & \multirow[t]{2}{*}{ Sig. (2-tailed) } \\
\hline & & Lower & Upper & & & \\
\hline Pair 1 & Pre-test - Post-test & -1.42800 & -.37200 & -3.382 & 99 & .001 \\
\hline
\end{tabular}


The $t$ value of -3.383 is well above the critical value of $t$ for a degree of freedom of 99 , at $p<.05$, which allows us to reject the second null hypothesis. The results show a significant difference between the scores of pretest and posttest, which proves the efficiency of treatment or teaching motivational strategies.

\subsection{Results of the Third Hypothesis}

This hypothesis concerns the weighing of the strategies by the learners and its possible relation to their performance on the reading post-test. Surprisingly, no significant correlation was found in this regard. But, this does not mean that the strategies employed by the teacher have not been effective. It should be pinpointed that the students' judgments of the effectiveness of these strategies may not be necessarily equated with their real effectiveness in practice. Table 4 shows the correlation between the use of motivational strategies and the participants' reading performance.

Table 4. Correlations Coefficient of the Motivational Strategies and Reading Performance

\begin{tabular}{ccccccccccc}
\hline Strategies & St. a & St. b & St. c & St. d & St. e & St. f & St. g & St. h & St. i & St. j \\
\hline $\begin{array}{l}\text { Reading } \\
\text { Ability }\end{array}$ & .154 & .155 & -.078 & -.054 & -.159 & .021 & .132 & .127 & -.004 & .134 \\
\hline
\end{tabular}

\subsection{Other Correlations}

Besides the findings that were addressed by the research questions, there were also other relations discovered. The first is that of the correlation of strategy $f$ "promote the students' awareness of the instrumental values associated with the knowledge of an L2" with b "take the students' learning very seriously" and c "promote the learners' language-related values by presenting peer role models". There are also a couple of other correlations, strategy e and g, as well as g and i. These correlations mean that those who rated high in one of the two variables in each pair also rated high in the other strategy in that pair. Table 5 presents more details on this correlation.

Table 5. Correlation of Strategies $\mathrm{b}$ and $\mathrm{f}$

\begin{tabular}{cccc}
\hline & & Strategy b & Strategy f \\
\hline Strategy b & Pearson & 1 & $.253^{*}$ \\
& Correlation & 100 & .011 \\
Strategy f & Pearson & $-.253^{*}$ & 1 \\
& Correlation & .011 & 100 \\
\hline
\end{tabular}

*Correlation is significant at the 0.05 level (2-tailed).

This correlation shows that one fourth of students who rated "take the students' learning very seriously" as important also did the same regarding "promote the students' awareness of the instrumental values associated with the knowledge of an L2". Table 4.6 deals with the way strategies c and $\mathrm{f}$ are related. The two variables are correlated at a significance level of 0.05 .

Table 6. Correlation of Strategies $\mathrm{c}$ and $\mathrm{f}$

\begin{tabular}{cccc}
\hline & & Strategy c & Strategy f \\
\hline Strategy c & Pearson & 1 & $.205^{*}$ \\
& Correlation & 100 & .041 \\
Strategy f & Pearson & $-.205^{*}$ & 1 \\
& Correlation & .041 & 100 \\
\hline
\end{tabular}

*Correlation is significant at the 0.05 level (2-tailed).

This correlation shows that some of the students who rated "promote the learners' language-related values by presenting peer role models" as important also considered "promote the students' awareness of the instrumental values, associated with the knowledge of an L2" very important. Table 7 concerns the relationship of strategies e and g. This correlation is significant at a level of 0.05 , and it is negative, which means that an increase in variable e led to a decrease in variable g. 
Table 7. Correlation of Strategies e and g

\begin{tabular}{cccc}
\hline & & Strategy e & Strategy g \\
\hline Strategy e & Pearson & 1 & $.234^{*}$ \\
& Correlation & 100 & .019 \\
Strategy g & Pearson & $-.234^{*}$ & 1 \\
& Correlation & .019 & 100
\end{tabular}

*Correlation is significant at the 0.05 level (2-tailed).

This means that the students who considered "promote 'integrative' values by encouraging a positive and open-minded disposition towards the L2, its speakers, and foreignness in general" significant also had the same idea about "make learning more stimulating and enjoyable by breaking the monotony of classroom events".

Table 8. Correlation of strategies $\mathrm{g}$ and $\mathrm{i}$

\begin{tabular}{cccc}
\hline & & Strategy g & Strategy i \\
\hline Strategy g & Pearson & 1 & $.204^{*}$ \\
& Correlation & 100 & .043 \\
Strategy i & Pearson & $.204^{*}$ & 1 \\
& Correlation & .043 & 100 \\
\hline
\end{tabular}

*Correlation is significant at the 0.05 level (2-tailed).

The students who considered "make learning more stimulating and enjoyable by breaking the monotony of classroom events" important also considered "increase students' motivation by promoting cooperation among the learners" important. There are implications to these findings in terms of language teaching in the classroom. These implications are discussed in the next section.

\section{Conclusion}

One finding of this study is about the interplay between the intelligences and reading proficiency. The verbal-linguistic intelligence was found in correlation with reading proficiency. This correlation is significant at the level of 0.01 . As the learners who enjoy a high linguistic intelligence are good at manipulating language, it seems that it affects their reading ability in the same way. The other intelligences were not found to be in such a relation with reading proficiency.

The next finding is the fact that applying the motivational strategies, introduced by Gardner et al. (2004) in the class, actually works. As mentioned before, teachers know from experience how much motivation is important in the class; however, incorporating a systematic framework, through which learners are kept motivated, requires more information. Through the treatment sessions, the strategies were classified and well-understood by the teacher. The $t$ value is significant at $\mathrm{p}<.0 .5$, which allows us to reject the null hypothesis of no significant relationship. This is an indication of the effectiveness of applying motivational strategies in the class.

It seems that before implementing such a framework in our classrooms, we should determine the relevance and effectiveness of these strategies. This is also possible by a teacher to informally try each strategy and find out about the feedback in terms of students' reactions and their effects in class achievement.

A further finding concerns the relationship between students' view of the effectiveness of each strategy and the results on the post-test. Surprisingly, no significant correlation was found in this regard. However, this does not mean that the strategies employed by the teacher were not effective since it was found that using these strategies was effective. It seems necessary to be pinpointed that the students' views on the effectiveness of these strategies may not necessarily be equated with their real effectiveness in practice. Their views might better be interpreted in terms of these strategies' psychological effect on the students.

The results of this study have some implications for language teachers. Language teachers often ignore implementing and teaching motivational strategies to the students. The may be due to some reason or other. They may be not aware of these strategies and be unfamiliar with the significant role of learners' motivation in the language learning process. They may even equate these strategies with language learning strategies, which are totally different in practice. They may know these strategies, but due to restricted available time for teaching the pre-dictated syllabus, they have to ignore teaching these strategies to the students. Unfortunately, although teaching motivational strategies to language learners is of particular importance, no place is devoted in the language teaching syllabus for them. Teachers can at least familiarize the students with these strategies through providing the students with appropriate supplementary materials with ample explanations and activities to reinforce the learners' motivation to learn a target language. The findings of 
this study reflected the positive correlation between applying these strategies and reading ability of the participants. Thus, language teachers can teach these strategies along with reading strategies simultaneously to foster reading process substantially. However, the problem resides in the unfamiliarity and inability of many language teachers to teach these strategies effectively to language learners. The problems can be resolved through effective teaching-training programs, which provide the teachers with ample knowledge and skills to teach these strategies to the students. On the other hand, the positive significant correlation, found between the verbal/linguistic intelligence and reading ability, suggests the importance of providing the language learners with the activities fostering their linguistic intelligence. Again, these activities are not present in the dictated language syllabus at secondary education level in Iran. Thus, the task of language teachers is to integrate these activities into the syllabus and improve the students' linguistic talents and skills.

\section{References}

Archer, J. (1994). Achievement goals as a measure of motivation in university students. Contemporary Educational Psychology, 19, 430-466. doi: 10.1006/ceps.1994.1031.

Bankier, J., \& Wright, A. (2012). Applying Dörnyei’s Motivational Strategies. In A. Stewart \& N. Sonda (Eds.), JALT2011 Conference Proceedings. Tokyo: JALT.

Deci, E.L., \& Ryan, R.M. (1985) Intrinsic Motivation and Self-Determination in Human Behavior. New York: Plenum.

Dev, P. C. (1997). Intrinsic motivation and academic achievement. Remedial and Special Education, 18 (10), $12-19$. doi: 10.1177/074193259701800104.

Dörnyei, Z. (2001). Motivational Strategies in the Language Classroom. Cambridge: Cambridge University Press.

Dörnyei, Z. (1995). On the Teachability of Communication Strategies. Tesol Quarterly, 29(1), 55 _85.

Gaines, D., \& Lehmann, D. (2002). Improving student performance in reading comprehension through the use of Multiple Intelligences. MA thesis, Saint Xavier University and Skylight Professional Development Field-based Master's Program. ED 467-515.

Garcia, T., \& Pintrich, P. R. (1996). The effects of autonomy on motivation and performance in the college classroom. Contemporary Educational Psychology, 21, 477-486.

Gardner, H. (1983). Frames of mind: The theory of multiple intelligences. New York: Basic Books.

Gardner, R. C., Masgoret, A.-M., Tennant, J., \& Mihic, L. (2004). Integrative motivation: Changes during a year-long intermediate-level language course. Language Learning, 54, 1-34. doi: 10.1111/j.1467-9922.2004.00247.x

Miller, R. B., Greene, B. A., Montalvo, G. P., Ravindran, B., \& Nichols, J. D. (1996). Engagement in academic work: The role of learning goals, future consequences, pleasing

Owolabi, T., \& Okebukola, F. (2009). Improving the reading ability of science students through study groups and multiple intelligences. US-China Education Review, 6(2), 38-43. 